\title{
Adaptive Neutron Radiography Correlation for Simultaneous Imaging of Moisture Transport and Deformation in Hygroscopic Materials
}

\author{
S.J. Sanabria - C. Lanvermann - F. Michel - D. Mannes • \\ P. Niemz
}

Received: 13 March 2014 / Accepted: 18 September 2014 /Published online: 21 October 2014

(C) Society for Experimental Mechanics 2014

\begin{abstract}
Neutron radiography is a key non-destructive testing technology for the investigation of moisture transport in materials. However, quantitative moisture measurements in swelling materials are currently challenging due to the lack of referencing between moist and dry state radiographs. A novel adaptive texture correlation algorithm is presented to simultaneously image inhomogeneous moisture distributions and moisture-induced strain fields. The proposed method provides a valuable tool for the study of time- and positiondependent hygromechanical interactions. Moreover, it requires no modification of existing neutron installations. The method was validated against gravimetric moisture content and optic surface deformation measurements. Its applicability was demonstrated for two actual topics in wood science, the investigation of moisture gradients within the growth ring microstructure and the study of moisture transport processes in wood-fiber composites. The algorithm can be widely used to characterize hygroscopic materials with heterogeneous
\end{abstract}

Electronic supplementary material The online version of this article (doi:10.1007/s11340-014-9955-2) contains supplementary material, which is available to authorized users.

S.J. Sanabria $(\varangle) \cdot$ C. Lanvermann $\cdot$ F. Michel $\cdot$ P. Niemz Institute for Building Materials ETH Zurich, Stefano-Franscini-Platz 6, CH-8093 Zurich, Switzerland

e-mail:ssanabria@ethz.ch

C. Lanvermann

e-mail: lanvermannchr@ethz.ch

F. Michel

e-mail: frmichel@ethz.ch

P. Niemz

e-mail: niemzp@ethz.ch

D. Mannes

Neutron Imaging and Activation Group, Paul Scherrer Institute, CH-5232 PSI, Villigen, Switzerland

e-mail: david.mannes@psi.ch texture, as frequently found in wood constructions, food industry, engineering and soil science.

Keywords Non-destructive neutron imaging $\cdot$ Heterogeneous texture correlation $\cdot$ Moisture-induced deformation strains . Wood composite materials $\cdot$ Mechano-sorptive rheology

\section{Introduction}

Neutron imaging (NI) is an established method to nondestructively study the dynamics of hydrogenous fluids, such as bound (hygroscopic) or free water molecules, in geomaterials (rocks, soils), engineered media (ceramics, polymers, metals, concrete, fuel cells, heat pipes, engines...) and biological composites (wood, food, natural fiber-reinforced composites..), among others. Compared to X-ray and Nuclear Magnetic Resonance (NMR) imaging, NI is highly sensitivity to hydrogen while being transparent to most solid-state materials, including heavy metals. Moreover, it allows dynamic full-field imaging in two (radiography) and three (tomography) dimensions with tenth-of-millimeter spatial resolution and sub-second measurement times [1-5].

Moisture intake in porous media is often accompanied by swelling, which is especially relevant for biological composites [6]. Wood is a classical example, volumetric swelling strains $>10 \%$ are not rare within its large hygroscopic range, which goes up to $30 \%$ moisture content from oven-dry state until the fiber saturation point (FSP), due to the hydrophilic behavior of the lignocellulosic cell walls. If not accounted for, swelling strain gradients can impair dimensional stability and induce eigenstresses, leading to cracking and delamination, which reduce the serviceability of wooden constructions [7]. Natural fiber-reinforced composites have drawn widespread attention in the last decades due to their low cost and biodegradability, accompanied by high strength and insulation 
properties [8]. However, their highly hygromorphic behavior is challenging. For example, the inner stresses induced in the hot pressing of wood-based fiber composites lead to larger thickness swelling than in raw wood material [9]. The coupling between moisture transport and deformation is also a key element to describe food drying, clay consolidation and sorption in polymer electrolyte fuel cells. Although sophisticated hygromechanical models are available, they often lack of accompanying experimental data. In this context, the simultaneous full-field imaging of moisture and moistureinduced deformation is necessary $[6,10-14]$.

Quantitative moisture measurements with neutrons also require hygro-expansion data. The gravimetric moisture content $\omega=m_{h} / m_{o}$ is defined in terms of the mass $m_{h}$ of water with respect to the mass of the dry solid phase $m_{o}$, which requires the local referencing of the neutron radiographs in moist $T$ state to the dry state $T_{o}$. Moreover, the density of the solid phase is lower in moist than in dry state due to sample swelling. Thus the in-plane swelling strain fields $\varepsilon_{i i}$ with respect to the reference dry state (Lagrangian description) need to be included in the calculation of $\omega$ (Equaton 1) [11, 15]:

$\omega=\left(1+\varepsilon_{X X}\right)\left(1+\varepsilon_{Y Y}\right) \rho_{h} z_{h}\left(\rho_{o} l_{z}\right)^{-1}$

with $l_{z}$ the sample thickness, $\rho_{h}$ and $\rho_{o}$ the densities of water $\left(10^{3} \mathrm{~kg} \mathrm{~m}^{-3}\right)$ and dry solid phase substance, respectively, and $z_{h}$ the effective water column thickness (Equaton 2):

$$
\begin{gathered}
Z_{h}=-\left[(\Sigma / \rho)_{h} \rho_{h}\right]^{-1}\left[\ln T-\ln T_{o}\left(1+\varepsilon_{X X}\right)^{-1}\left(1+\varepsilon_{Y Y}\right)^{-1}\right] \\
\rho_{o}=-\ln T_{o}\left[(\Sigma / \rho)_{o} l_{z}\right]^{-1}
\end{gathered}
$$

$(\Sigma / \rho)_{h}$ and $(\Sigma / \rho)_{o}$ are respectively the mass-attenuation coefficients in water and solid phases. For the energy spectrum of the thermal neutron beamline NEUTRA at the Paul Scherrer Institute (Villigen, Switzerland) [41], where the presented investigations were carried out, $(\Sigma / \rho)_{o}=0.18 \mathrm{~m}^{-2} \mathrm{~kg}^{-1}$ for wood (Table 1, [42]) and $(\Sigma / \rho)_{h}=0.35 \mathrm{~m}^{-2} \mathrm{~kg}^{-1}$ for water [43]. Operating Equation 1 shows that neglecting hygroscopic strains of $10 \%$ in wood leads to unacceptable quantitative moisture errors over $5 \%$ (absolute error), as shown in Equation 3:

$$
\begin{aligned}
\omega= & \omega_{\mid \varepsilon=0}\left[1+\varepsilon_{X X}+\varepsilon_{Y Y}\right] \\
& +(\Sigma / \rho)_{o}\left[(\Sigma / \rho)_{h}\right]^{-1}\left[\varepsilon_{X X}+\varepsilon_{Y Y}+\varepsilon_{X X} \varepsilon_{Y Y}\right] \approx \omega_{\mid \varepsilon=0} \\
& +0.52\left[\varepsilon_{X X}+\varepsilon_{Y Y}\right]
\end{aligned}
$$

Finally, the edge misalignment induced by hygroexpansion leads to unbounded errors and non-physical moisture values at image discontinuities, which impedes or makes the study of moisture transport through multi-layered composites and surface coatings challenging $[16,17]$.

These shortcomings have so far been alleviated with a global pre-registering of neutron radiographs based on sample edge detection [18-21], which reduces edge misalignment, but does not account for inner deformation gradients. Fullfield strain measurements with neutrons have been achieved in some crystalline materials by using a tunable monochromatic beam, for which Bragg cut-off wavelengths provide lattice spacing [1]. Yet a combination with moisture measurements has not been reported. NI was recently combined with optical deformation measurements [15]. Although accurate high-resolution $\varepsilon_{i i}$ measurements were obtained, the setup requires sample speckling and an involved synchronized camera installation. Moreover, only surface deformation is measured, which leads to significant edge misalignment artifacts in volumetric samples.

In this work, a novel Adaptive Neutron Radiography Correlation (ANRC) algorithm is presented, which uses the texture information in neutron images to locally estimate the strain fields. This method is exclusively based on the postprocessing of radiographs, therefore requiring no modification of existing neutron installations, and providing average deformation estimates over the sample thickness. The new approach is validated with gravimetric and optic methods. Its potential and applicability are demonstrated for two actual research topics in wood science:

a) Gradients in moisture and hygroscopic swelling in softwood growth rings [15, 16, 22-25]

b) Investigation of moisture transport through swelling wood-fiber composites $[3,17,18,26]$

\section{Adaptive Neutron Radiography Correlation (ANRC)}

The starting point for the ANRC algorithm is a set of neutron radiographies of the test samples, which are experimentally acquired at well-controlled dry and moist states. State of the art corrections are first applied to compensate for source and detector inhomogeneities (CCD dark current, median filter, intensity normalization, flat field correction, spectral effects), background scattering (black body calibration) and sample scattering (Monte-Carlo simulations) [43].

Figure 1 summarizes the building blocks of the ANRC algorithm. The inner core performs Digital Image Correlation (DIC) processing. Subsets of the reference image $I^{r e f}$ (dry state) are automatically searched at specific positions $r$ of the deformed image $I^{\text {test }}$ (moist state), resulting in local estimates of the deformation vector $\mathrm{u}(\mathrm{r})$, from which the strains fields $\varepsilon_{i j}$ are differentiated. The DIC method is wellknown and performs best for artificial random speckle 
Table 1 Summary of neutron attenuation properties, ANRC settings and correlation statistics for the investigated test materials

\begin{tabular}{|c|c|c|c|c|c|c|c|c|c|}
\hline & $\rho_{o}\left(\mathrm{~kg} \mathrm{~m}^{-3}\right)$ & $(\Sigma / \rho)_{o}\left(\mathrm{~m}^{-2} \mathrm{~kg}\right)$ & $\mathrm{d}(\mathrm{m})$ & $\Delta(\mathrm{mm})^{\mathrm{b}}$ & $s_{\rho} / \rho(\%)^{\mathrm{c}}$ & CNR (a.u.) ${ }^{\mathrm{c}}$ & $r$ (a.u.) & $e=1(\%)$ & $\mathrm{u}^{\max }(\mathrm{mm})$ \\
\hline $\begin{array}{l}\text { I: Optical, softwood growth } \\
\text { rings }^{\mathrm{a}} \text { (Fig. 2, 4.1.1) }\end{array}$ & n.a. (not applicable) & n.a. & n.a. & {$[0.2,0.2]$} & n.a. & 4.6 & 0.96 & {$[0.7,0.7]$} & {$[1.5,1.0]$} \\
\hline $\begin{array}{l}\text { II: Neutron, softwood growth } \\
\text { rings }{ }^{\mathrm{a}} \text { (Fig. 3-6, 4.1.2) }\end{array}$ & 362 & 0.18 & 0.005 & {$[2.9,2.9]$} & 34 & 5.1 & 0.98 & {$[0.5,16]$} & {$[0.8,1.7]$} \\
\hline \multicolumn{10}{|l|}{$\begin{array}{l}\text { III: Neutron, wood-fiber } \\
\text { composites }^{\text {a }} \text { (Fig. 7-8, 4.2) }\end{array}$} \\
\hline Isonat chanvre & 44 & 0.27 & 0.04 & {$[4.5,9]$} & 15 & 2.5 & 0.92 & {$[0,0]$} & {$[0.2,0.04]$} \\
\hline Pavaflex & 48 & 0.23 & 0.04 & {$[4.5,9]$} & 16 & 2.5 & 0.91 & {$[0,0]$} & {$[0.2,0.08]$} \\
\hline Pavatherm & 135 & 0.19 & 0.04 & {$[4.5,9]$} & 6 & 1.2 & 0.76 & {$[0,0]$} & {$[0.1,0.04]$} \\
\hline Aerogel Vliesmatte & 147 & 0.10 & 0.04 & {$[4.5,9]$} & 9 & 1.6 & 0.88 & {$[0,0]$} & {$[0.3,0.2]$} \\
\hline Isoroof-natur-KN & 225 & 0.18 & 0.04 & {$[4.5,9]$} & 6 & 1.1 & 0.64 & {$[1.6,1.4]$} & {$[0.6,0.2]$} \\
\hline
\end{tabular}

${ }^{\text {a }}$ The pixel sizes for I, II and III are 23, 77 and $145 \mu \mathrm{m}$, respectively

${ }^{\mathrm{b}}$ Fixed algorithm settings (px): $\mathrm{W}_{\mathrm{S}}=[3,3], \mathrm{W}_{\mathrm{L}}=[5,5], \Delta \mathrm{u}^{\max }=[3,3], N_{e}=5, N_{\hat{u}}=[10,100]$

${ }^{\mathrm{c}} s_{\rho}$ is the standard deviation of the dry material density $\rho_{o}$ within the correlated subsets. CNR $=\mathrm{s}_{\Delta} / \mathrm{s}_{\mathrm{n}}$, with $\mathrm{s}_{\Delta}$ and $\mathrm{s}_{\mathrm{n}}$ respectively for correlation subset and background image noise. $s_{\Delta}=s_{\rho}(\Sigma / \rho)_{o} l_{Z} \exp \left[-\rho_{o}(\Sigma / \rho)_{o} l_{Z}\right]$ for the neutron images $T$, following from Equation 2. $s_{\mathrm{n}}=0.02$ for all radiographs

patterns, where unique subset correspondence is satisfied. Typical DIC parameters are subset size, search function and region and deformation order [27]. Many heterogeneous materials show enough natural texture to track $\mathrm{u}$ without need of artificial sample speckling, the DIC process is then specifically termed Texture Correlation (TC) [28]. Neutron radiographs of wood composites are assumed to show enough texture for TC, which is empirically confirmed by the high correlation statistics observed in the investigated test samples (Table 1).
The proposed ANRC processing is thus a TC algorithm, which is optimized and expanded to robustly extract deformation information from NI radiographs while ignoring "shadow regions", where only poor correlation statistics are available. With this purpose, the DIC core implements a zeroorder search (rigid subsets). A zero-normalized cross-correlation function $I^{\text {corr }}$ (Equation 4) is calculated at each integer pixel position within a search window $\mathrm{W}$ for a subset size $\Delta$. The peak maximum $r$ provides the displacement vector $\mathrm{u}$, which is refined by applying bicubic interpolation to $I^{\text {corr }}$ :

$I_{\text {corr }}(\widehat{x}, \widehat{y})=\left(\frac{\sum_{x, y \in \Delta}[T(x-\widehat{x}, y-\widehat{y})-\bar{T}]\left[T_{o}(x, y)-\overline{T_{o}}\right]}{\sum_{x, y \in \Delta}[T(x-\widehat{x}, y-\widehat{y})-\bar{T}]^{2} \sum_{x, y \in \Delta}\left[T_{0}(x, y)-\overline{T_{0}}\right]^{2}}\right)^{-1} \mathbf{u}=\underset{\widehat{x}, \widehat{y} \in \mathbf{W}}{\arg \max _{\text {corr }}}$

In order to minimize false correlation hits, the search region is adaptively adjusted. The algorithm starts searching in a large reset window $\mathrm{W}_{\mathrm{R}}$. Subsequent search positions $\mathrm{r}^{i}$ are ordered in a raster scan of the reference image. For each of them, the search is reduced to a shorter window $\mathrm{W}_{\mathrm{S}}$ centered at an initial deformation estimate $\hat{u}$, which is calculated based on the linear extrapolation of $N_{\hat{u}}$ neighboring pixels. An error control block ensures the well-posing of the estimated $u$ by controlling its: a) correlation: the correlation coefficient $r$ is above a minimum threshold $r^{\min }$, b) uniqueness: $\mathrm{u}$ is within image bounds, is not an edge pixel of $I^{\text {corr }}$, and does not exceed a maximum deformation value $\mathrm{u}^{\max }, \mathrm{c}$ ) continuity: $\mathrm{u}$ does not increase by more than $\Delta \mathrm{u}^{\max }$ in each iteration. In the case of an error of type b), a second trial is admitted with a larger window $\mathrm{W}_{\mathrm{L}}$ before discarding $u$. Only non-error u values $(e=0)$ are used for the adaptive search and the continuity error check. Ill-posed $\mathrm{u}(\mathrm{e} \neq 0)$ increment the error count $c_{e}$ up to a threshold $N_{e}$. Then the reset control block starts operation, deactivating the adaptive search and resetting the search window to $\mathrm{W}_{\mathrm{R}}$. The algorithm manages errors along individual dimensions of the deformation vector $u_{j}$ by only storing well-posed $u_{j}$. The loss of continuity upon reset is additionally avoided by managing an additional reset count $c_{R}$ and not accepting $\mathrm{u}$ values at first reset positions $\left(c_{R}=1\right)$ for updating the deformation estimate $\hat{u}$, by using at reset positions $\hat{u}$ instead of $\mathrm{u}$ for continuity control, and by filtering out isolated $\mathrm{u}$ pixels. 


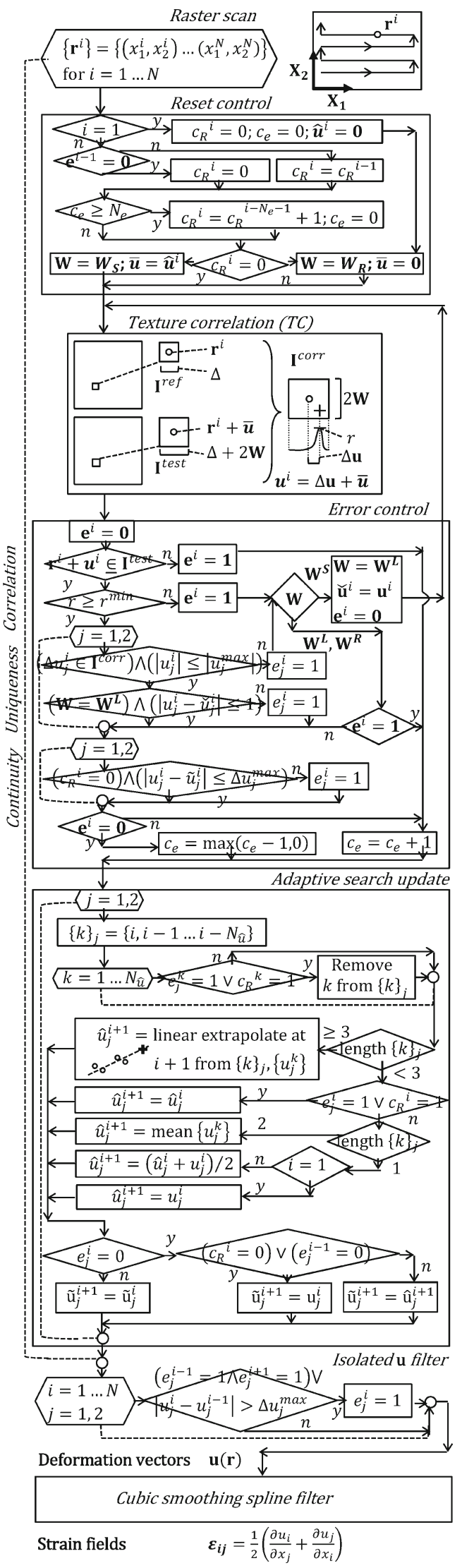

Fig. 1 Flow diagram of ANRC algorithm
Continuous deformation fields are calculated by fitting the estimated deformation vectors $\mathrm{u}$ to cubic smoothing splines $f\left(\mathrm{r}^{i}\right)$ (Equation 5), which trade-off between data fidelity and smoothness [29]:

$\sum_{i=1}^{N} r^{i}\left|u_{j}^{i}-f\left(\mathbf{r}^{i}\right)\right|^{2}+(1-p) \int D^{2}|f(t)|^{2} d t \quad p=\left(1+h^{3} / 6\right)^{-1}$

The weights of the error function are adjusted to the peak correlation coefficients $r$. The resolution $h$, which controls the smoothness, is adjusted with the subset size in the range $h=\Delta / 3 \ldots \Delta$. The fitted spline functions are finally differentiated to compute the strain fields $\varepsilon_{\mathrm{ij}}$. In order to minimize noise sensitivity, only first order derivatives are included in $\varepsilon_{\mathrm{ij}}=0.5\left(\partial u_{\mathrm{i}} / \partial x_{\mathrm{j}}+\partial u_{\mathrm{j}} / \partial x_{\mathrm{i}}\right)$.

The settings of ANRC for each case study are summarized in Table 1. The subset size $\Delta$ is a trade-off between wellposing and lateral resolution of $\mathrm{u}$. A threshold $\Delta$ is typically found, above which correlation statistics do not significantly improve. The ANRC algorithm was implemented in Matlab ${ }^{\circledR}$ (R2011b, The Mathworks Inc., Natick, MA, USA) and is provided in the supplementary materials for free use and development (Supp. Mat.).

\section{Experiments}

Moisture and Swelling Gradients in Softwood Growth Rings at Hygroscopic Equilibrium

\section{Optical surface deformation measurements}

The strain field $\varepsilon_{i j}$ calculation with ANRC was first quantitatively validated against a commercial DIC tool (VIC 2D 2009, Correlation Solutions Inc., USA) for high-resolution optical images of speckled softwood (Fig. 2). The DIC measurements were previously used to investigate wood cross-grain hygroexpansion at the growth ring structural level $[15,24]$. The goal was to identify swelling strain gradients between the alternating bands of low-density earlywood (EW)- thin-wall wood cells with large internal lumens grown in spring - and high-density latewood (LW) - thick-wall cells with small-sized lumens grown in summer (Fig. 2a). Four cuboid samples $\left(40 \times 40 \times 5 \mathrm{~mm}^{3}\right)$ were cut from a Norway spruce (Picea abies Karst.) stem, their edges were well-aligned with respect to the main wood material axes (radial $\mathrm{R} \times$ tangential $\mathrm{T} \times$ longitudinal $\mathrm{L}$ ). The samples were sprayed with a black/white speckle pattern by means of an airbrush gun with a nozzle size of $0.2 \mathrm{~mm}$. They were then subjected in a portable climatic chamber to a moisture sorptiondesorption cycle with relative humidity (RH) adjusted in $15 \%$ steps between 0 and $95 \%$. For each nominal RH state, the samples were conditioned to equilibrium moisture content and optical images were acquired with a CCD camera (Fig. 2b). The 
Fig. 2 Quantitative validation of ANRC processing on high-resolution CCD camera images. a) Test Norway spruce samples. The growth ring microstructure is illustrated at cellular scale with LM and at subcellular scale with ESEM. b) Optical surface images at dry $(\mathrm{RH}=0 \%)$ and moist $(\mathrm{RH}=95 \%)$ states, correlation subsets $I^{\text {ref }}, I^{\text {test }}$ and search functions $I^{\text {corr }}$ are highlighted. c) shows hygroscopic strain fields calculated from $b$ ) with both ANRC and a commercial DIC tool, which in d) are averaged and plotted in function of the growth ring position $\varphi$

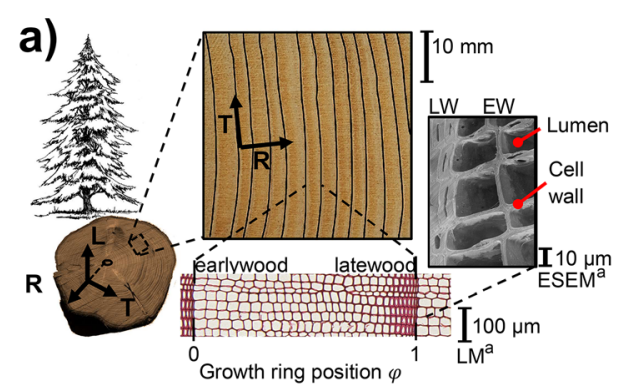

b)
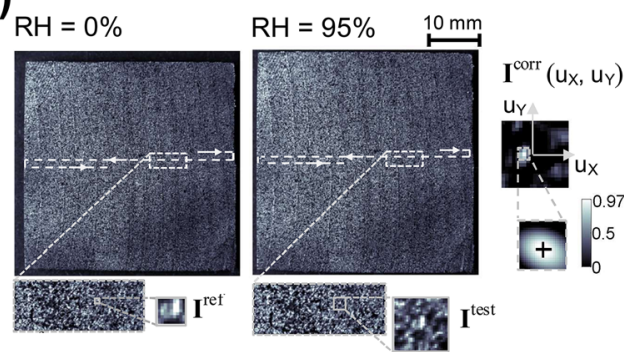

c) $\varepsilon_{X X}(\%)$

d)

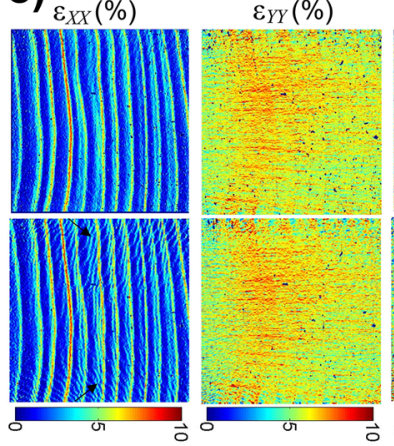
$\varepsilon_{X Y}(\%)$
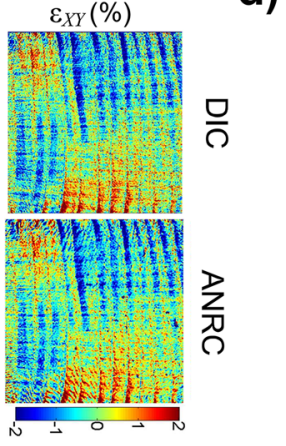

aLM: Light microscopy, ESEM: Environmental scanning electron microscopy

oven-dry state $(\mathrm{RH}=0 \%)$ was used as reference. Next, the inplane swelling strains were calculated with ANRC and compared to the commercial DIC results (Fig. 2c). The subset size $\Delta$ was $9 \times 9$ pixels ${ }^{2}$ for both methods, for a pixel size of $23 \mu \mathrm{m}$. Finally, the strains were transformed with respect to the material axes $(\mathrm{R}, \mathrm{T})$ and plotted in function of the relative growth ring position $\varphi=0 \ldots 1$, with 0 and 1 respectively defining EW and LW regions (Fig. 2d) . The coordinate transformation method is further detailed in $[15,24]$.

\section{Simultaneous neutron imaging of moisture content and moisture-induced deformation}

The moisture and strain gradients within the growth rings were investigated at equilibrium conditions with NI at the thermal neutron beam line NEUTRA at the Paul Scherrer Institute in Villigen, Switzerland. The experimental setup consists of a neutron beam collimator, a neutron detector and a portable climate chamber (Fig. 3a) and has been detailed in [15]. The neutron radiographs (Fig. 3b) show a pixel size of $145 \mu \mathrm{m}$ and a lateral resolution of $\sim 0.7 \mathrm{~mm}$ (minimum detectable line spacing). The deformation vectors $\mathrm{u}$ and strain fields $\varepsilon_{i j}$ at each RH step were computed with ANRC and a subset size $\Delta$ of $21 \times 21$ pixels $^{2}$ (Fig. 4). The moisture content distribution $\omega$ was calculated with Equation 1 and plotted in function of the growth ring position (Fig. 5).

The average $\omega$ values were validated gravimetrically (Fig. 6). At each RH state the weight of the sample was recorded with $0.1 \mathrm{mg}$ accuracy with a precision scale. The local moisture and strain fields were validated with the combined NI and optical surface deformation measurement setup of [15]. With this purpose, a stereo-vision installation (Fig. 3a) consisting of two radiation-shielded $\mathrm{CCD}$ cameras and cold-light illumination captured optical images from the sample laterals without perturbing the neutron line of sight. The surface deformation vectors $\mathrm{u}$ were then calculated with commercial DIC (VIC3D, Correlated Solutions). As in 3.1.1, a subset size $\Delta$ of $9 \times 9$ pixels $^{2}$ was used, the resolution was here lower due to the optical constraints (pixel size $77 \mu \mathrm{m}$ ). The optical images (Fig. 3c) and the neutron radiographs were referenced with fiducial markers. The calculated deformation vectors were then used to align the neutron radiographs and to compute $\omega$.

Transient moisture diffusion and moisture-induced swelling in wood-fiber composites

The applicability of the ANRC algorithm to simultaneously investigate dynamic moisture transport and the large coupled deformations in biological composites was demonstrated for a selection of multi-layer building insulation materials. Three commercial wood fiberboards (Pavaflex, Pavatherm and Isoroof-natur-KN from Pavatex SA, Fribourg, Switzerland), a hemp fiber composite (Isonat chanvre from Valnaturel SA, Saxon, Switzerland) and a nanoporous aerogel (Aerogel Vliesmatte from Aspen Aerogels Inc., Northborough, MA, USA) were tested (Table 1). The material properties are detailed in $[26,30]$. The test objects $\left(40 \times 40 \mathrm{~mm}^{2}\right.$ section $)$ were typical three-layer insulation combinations, with two $20 \mathrm{~mm}$ thick Isoroof outer layers and a $35 \mathrm{~mm}$ (Isonat, Pavatherm, Pavaflex) or a $5 \mathrm{~mm}$ thick (Aerogel) middle layer. Following 
Fig. 3 a) Neutron transmission setup for imaging of moisture-induced deformation, together with optical feedback for validation of ANRC strain field estimation. Sample neutron radiographs b) and CCD camera images c) are also shown a)
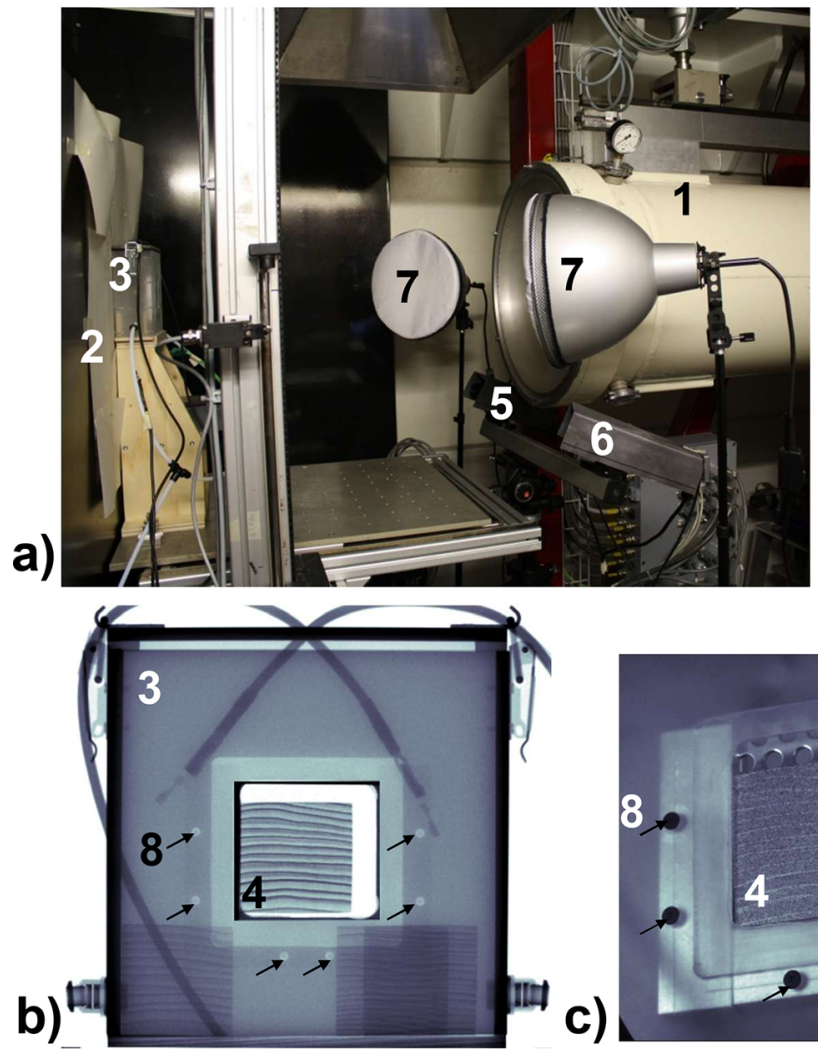

Neutron setup

1: Neutron beam collimator

2: Neutron detector

3: Climate chamber

4: Test sample

Optical setup

5: CCD camera 1

6: CCD camera 2

7: Illumination

8: Fiducial markers

(steel screws)

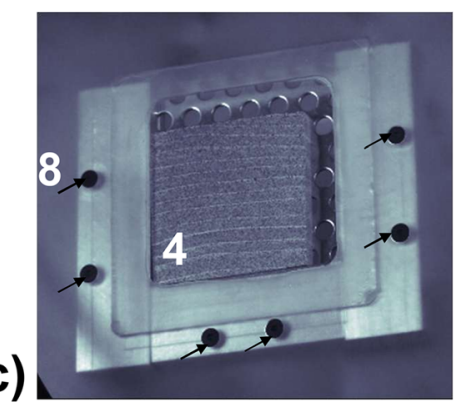

the experimental setup of [3, 17], six samples were ovendried, sealed with aluminum tape on the four lateral surfaces and placed in a climatic box $\left(\mathrm{RH}=84 \%, \mathrm{~T}=31{ }^{\circ} \mathrm{C}\right)$ above a desiccating silica gel. This ensures a unidirectional moisture transport from top to bottom sample surfaces. Neutron radiographs were regularly acquired at NEUTRA during $17 \mathrm{~h}$ (same $145 \mu \mathrm{m}$ pixel size as in 3.1.2) (Fig. 7a). To highlight the natural texture in the images, for each vertical position, the mean value was subtracted from the horizontal profiles, which were subsequently normalized to their a) $\mathrm{RH}=0 \%$
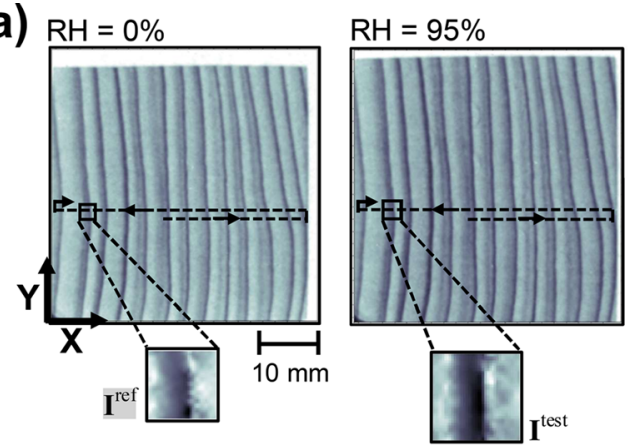

$T($ a.u. $)$

1.0

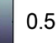

0.5

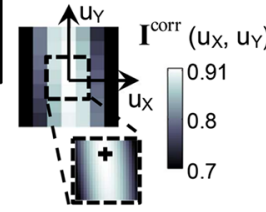

c)
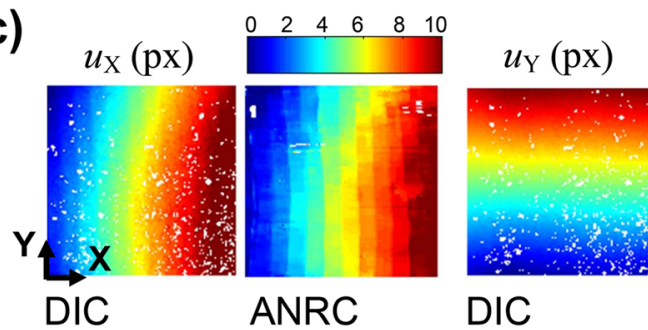

$\begin{array}{llllll}-5 & 0 & 5 & 10 & 15 & 20\end{array}$
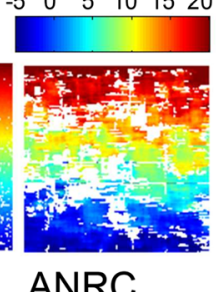

Fig. 4 Quantitative validation of ANRC processing on neutron images. a) Neutron radiographs corresponding to the test Norway spruce sample of Fig. 2. b) Evolution of ANRC variables during b)
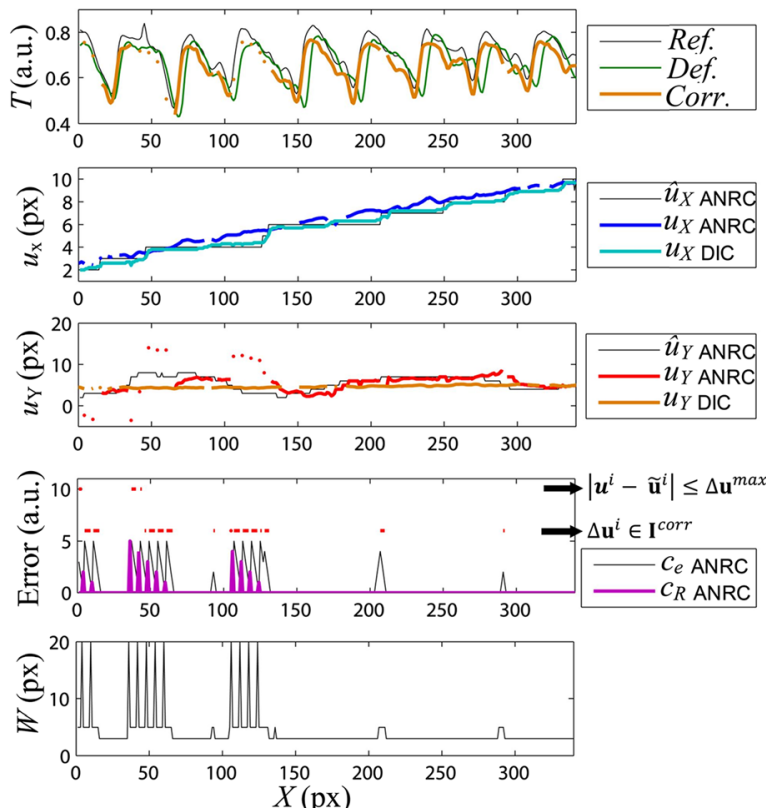

raster scan of layered growth ring structure. c) Comparison of deformation fields calculated directly from neutron radiographs (ANRC) with respect to optic surface measurements (DIC) 
Fig. 5 Moisture and swelling gradients within Norway spruce growth rings at hygroscopic equilibrium. a) Average density profile $\rho$ estimated from neutron measurements. b) and c) show the strain fields $\varepsilon_{\mathrm{TT}}$ and $\varepsilon_{\mathrm{RR}}$ measured with the optical setup of Fig. $4 \mathrm{a}$ (DIC) and directly estimated from the neutron radiographs (ANRC). Moisture content profiles were calculated: by using DIC d) and $\mathrm{ARNC}$ e) for both neutron radiograph registration and swelling strain estimation, and f) by using ANRC for radiograph registration and DIC for swelling strain estimation
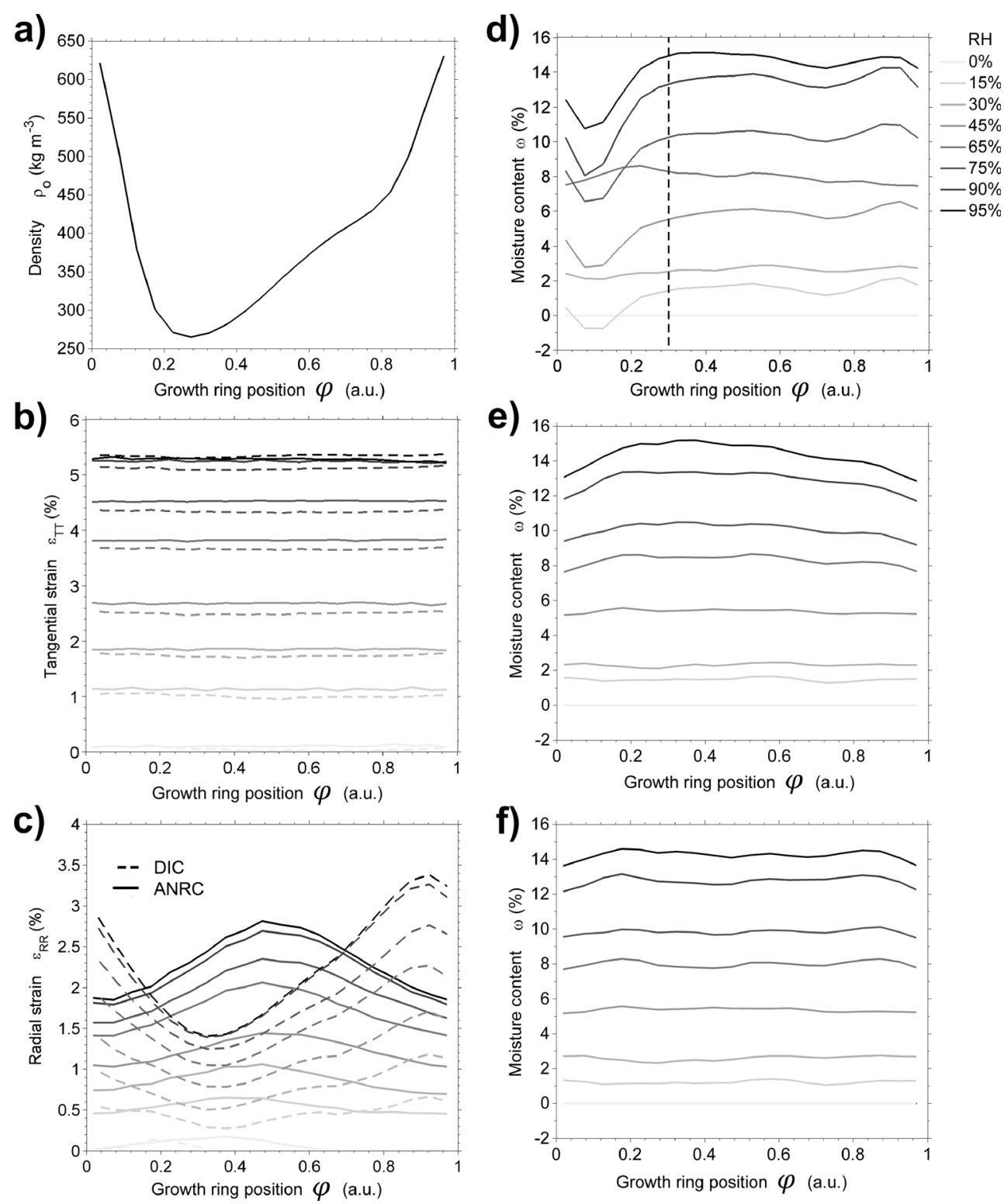

standard deviation (Fig. 7b). The images were then processed with ANRC with a subset $\Delta$ of $31 \times 61$ pixels $^{2}$ (thickness $\mathrm{Y} \times$ width $\mathrm{X}$ ) to calculate strain fields (Fig. 7c) and moisture concentrations (Fig. 7d).

Under fiber saturation, moisture transport in wood occurs due to diffusion, both as water vapor in the cell lumens and as bound water in the cell walls. The mass portion of water vapor is very small, leading to negligible neutron attenuation, the bound water concentration scales with $\omega$. The unsteady-state diffusion is in a first approximation described by Fick's second law [17]:

$\partial_{t} \omega=\partial_{y}\left(D_{U S} \delta_{y} \omega\right)$

The diffusion coefficients $D_{U S}\left(\mathrm{~m}^{2} \mathrm{~s}^{-1}\right)$ for each material layer were iteratively optimized $[17,18]$ by fitting the experimental time-dependent moisture fields $\omega(x, y, t)$ to finite-difference time-domain solutions of Equation 6 (Fig. 8a). The results were compared to average steady state coefficients $D_{S S}$ calculated with the standardized dry/wet cup method for each of the materials [26] (Fig. 8b). Finally, the time-evolution of the hygroscopic strains with respect to $\omega$ was investigated (Fig. 8c-e).

\section{Results and Discussion}

The comparison of ANRC correlation statistics for specific test scenarios shows distinctive trends (Table 1). The texture quality is well-summarized with a contrast to noise ratio CNR between the standard deviation of the correlation subset $s_{\Delta}$ 

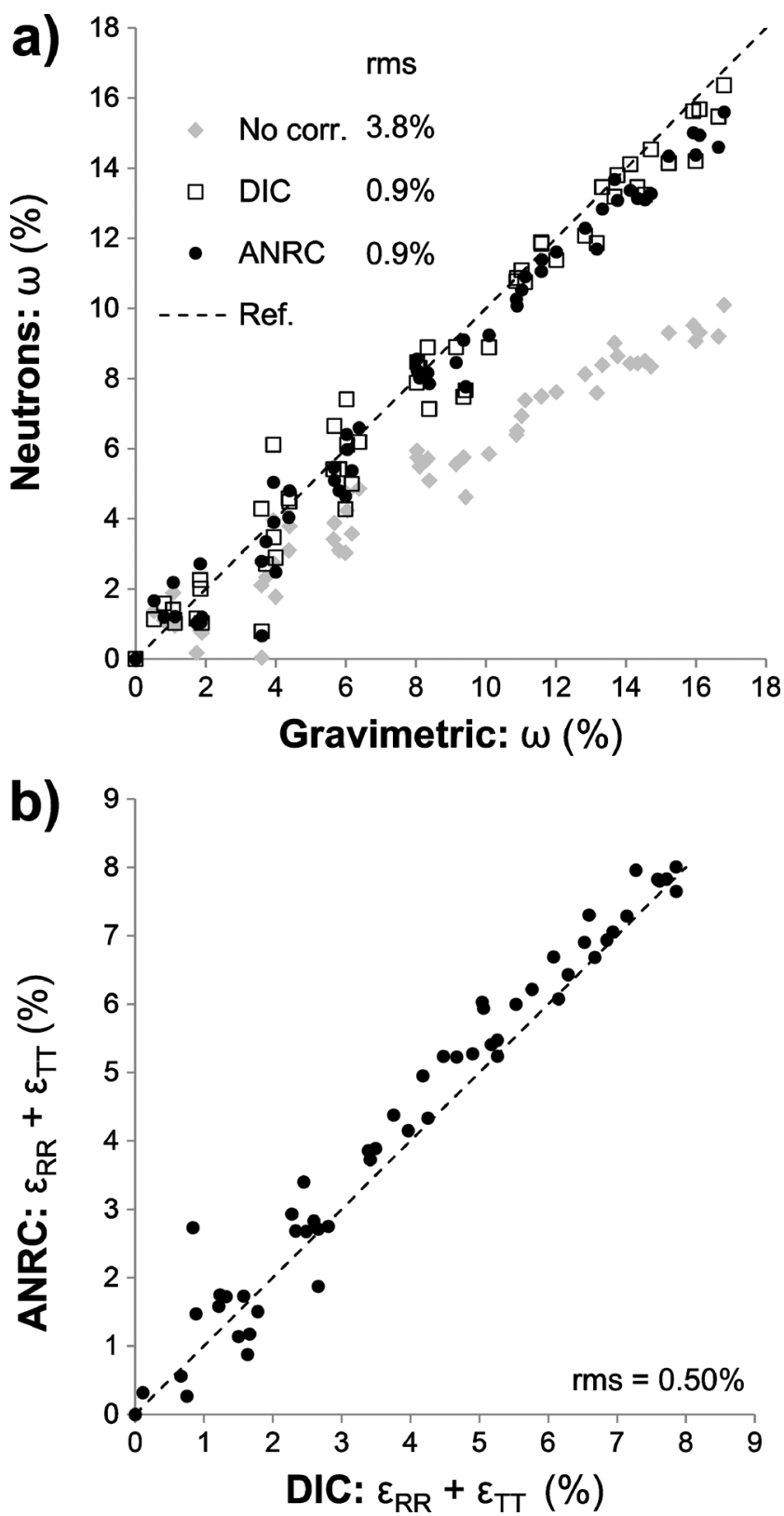

Fig. 6 a) Comparison of average gravimetric moisture content $\omega$ for each test sample with neutron values obtained without correction for hygroscopic swelling (no corr.), by using the optical setup of Fig. 4a for the correction (DIC), and by estimating the swelling fields directly from the radiographs (ANRC). b) Comparison of average swelling strains calculated with ANRC and DIC

and the background image noise $s_{n}$. Higher CNR lead to larger correlation coefficients $r$ and, for the same image resolution, allow for smaller subset sizes $\Delta$. The CNR is directly correlated with the density variability within the subset $s_{\rho} / \rho$. For wood-fiber composites, $s_{\rho} / \rho$ shows a decreasing trend with higher density $\rho$. Since the lignocellulosic wood cell walls are essentially homogeneous [31], the density variability is directly related to the heterogeneity of wood's porous microstructure. The porosity is reduced with higher densification, which leads to lower $s_{\rho} / \rho$ (Fig. 2a). The ratio of ill-posed u $(\mathrm{e} \neq 0)$ was reduced to $<0.1 \%$ for $r>0.7$ by carefully selecting the subset size $\Delta$. The exceptions were the neutron radiographs of softwood growth rings (Fig. 4). In this case, unique subset correspondence was only satisfied along one image direction, which led to a minimum of $16 \%$ error values, even with the highest correlation coefficients $r=0.98$. This scenario is detailed in 4.1.2.

Moisture and Swelling Gradients in Softwood Growth Rings at Hygroscopic Equilibrium

\section{Optical surface deformation measurements}

Based on Fig. 2, the anisotropic swelling mechanisms within the growth ring are briefly reviewed [24, 25]. Swelling strains are caused by water sorption in the cell wall and become more pronounced with higher relative humidity $\mathrm{RH}$ and adsorbed moisture content $\omega$. The radial strains $\varepsilon_{X X}$ are thus determined by the cell wall fraction, which scales linearly with the oscillatory growth ring density profile. The intra-ring density profile increases monotonically between EW and LW regions, with a sharp discontinuity at LW-EW transitions (Fig. 5a). In tangential direction, the stiffer LW cells force the EW cells to swell to the same extent, leading to uniform strains $\varepsilon_{Y Y}$. The small shear strains $\varepsilon_{X Y}$ are due to the free swelling of the sample edges.

The strain distributions calculated from optic images with ANRC and commercial DIC were in excellent agreement (Fig. 2c). A quantitative pixel wise comparison revealed rms errors of $0.5 \%$ for $\varepsilon_{X X}$ and $\varepsilon_{Y Y}$ and $0.4 \%$ for $\varepsilon_{X Y}$. These uncertainties are essentially random and are significantly reduced for the average growth ring profiles (Fig. 2d), with $0.03 \%$ for $\varepsilon_{T T}, 0.11 \%$ for $\varepsilon_{R R}$ and $0.01 \%$ for $\varepsilon_{R T}$. The higher errors for $\varepsilon_{R R}$ are associated to streaking artifacts (arrows in $\varepsilon_{X X}$, Fig. 2c), due to the sharp strain transitions across LW-EW boundaries. The uncertainties were traced back to the $\mathrm{u}$ computation ( 0.05 pixels) and the zero-order search implemented in ANRC. In comparison, the commercial DIC tool uses an iterative scheme incorporating affine subset deformation [27]. The leads to superior accuracy for rotational displacements, but has the drawback of loss of convergence with low correlation statistics, which are typical of texture correlation (TC) [28]. In fact, on the contrary to ANRC, the commercial DIC tool was unable to retrieve $\mathrm{u}$ data from neutron radiographs (Fig. 4a, 4.1.2). Since hygromechanical strains are essentially of swelling nature, the zero-order implementation achieves a good trade-off between accuracy and robustness.

Simultaneous neutron imaging of moisture content and moisture-induced deformation

A qualitative comparison of the neutron radiography (Fig. 4a) subsets $\left(I^{\text {ref }}, I^{\text {test }}\right)$ and correlation functions $\left(I^{\text {corr }}\right)$ with their 

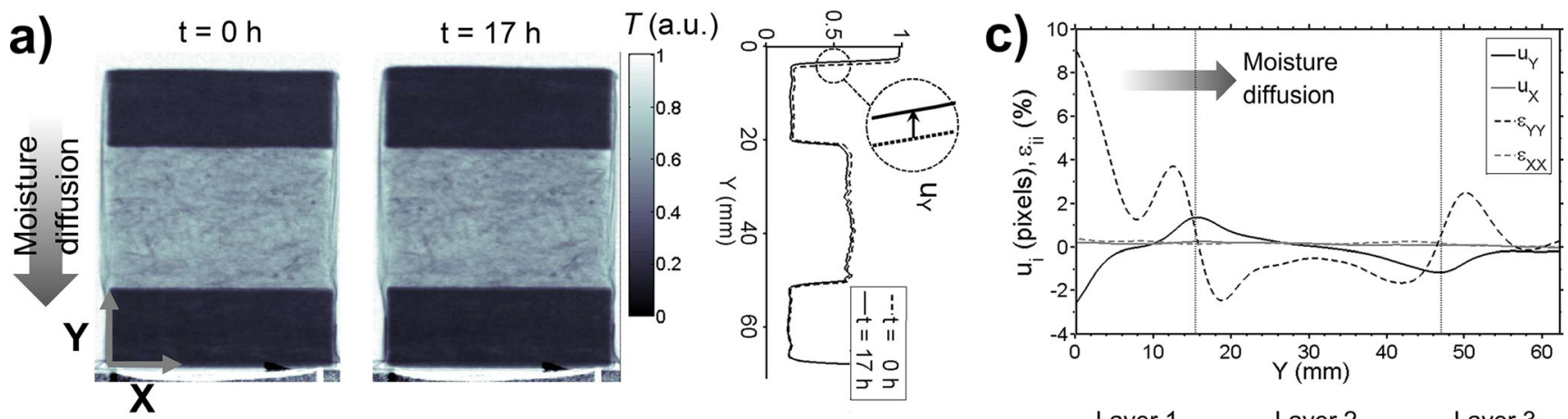
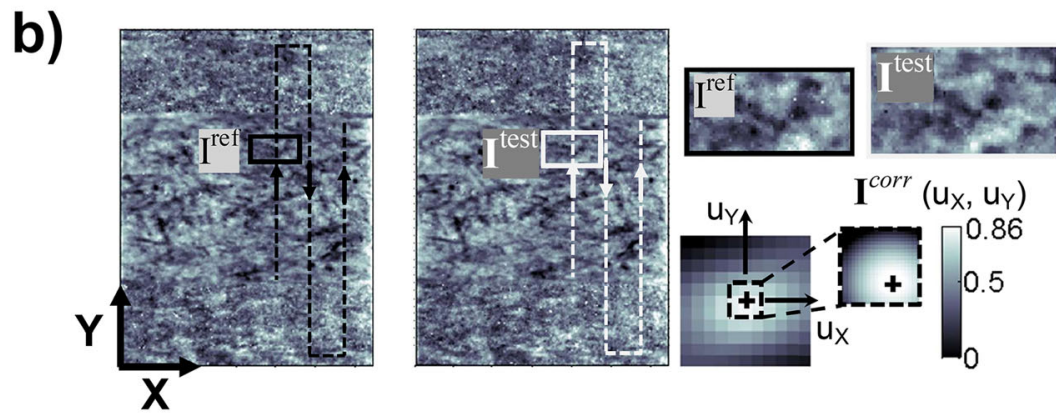

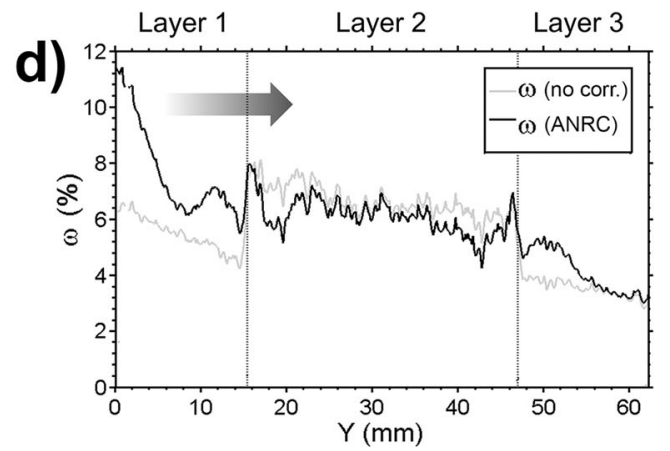

Fig. 7 Applicability of ANRC to investigate hygroscopic transport in highly hygromorphic composites. a) Neutron radiographs of IsoroofPavaflex-Isoroof ${ }^{\mathbb{R}}$ wood-fiber composite at the beginning $(\mathrm{t}=0 \mathrm{~h})$ and end $(t=17 \mathrm{~h})$ of unidirectional diffusion experiment. b) Preprocessed

optical counterparts of Fig. $2 \mathrm{~b}$ shows fundamental differences. While the random speckle pattern of the optic images leads to unique correlation peaks, the layered growth ring structure shows quasi-symmetric neutron transmission patterns along the tangential direction $\mathrm{Y}$, which are translated into $I^{\text {corr }}$. Therefore, unique subset correspondence is only poorly satisfied along Y. The ANRC algorithm dealt satisfactorily with this unfavorable deformation tracking scenario. The transmission profiles $T$ in the deformed image were well-aligned with the reference image after correction (Fig. 4b). The ANRC uniqueness and continuity error control correctly sorted out ill-posed deformation values, while preserving the adaptive deformation tracking û. The robust reset control ensured that the search region $\mathrm{W}$ increased after the maximum error count $e_{c}$ was exceeded, while rejecting deformation outliers leading to continuity loss (isolated values in $u_{Y}$ profile). The independent error management for $u_{X}$ and $u_{Y}$ allowed that well-posed $u_{X}$ were resolved except for $0.5 \%$ of the tracked surface (Table 1). The natural curvature of the growth rings provided enough information to determine $u_{Y}$ for most of the radiograph. The $16 \%$ unresolved $u_{Y}$ pixels (white areas in Fig. 4c) occur at positions where the LW-EW layers are almost parallel to X. A remarkable benchmark of ANRC performance is that the error statistics remained stable with the same algorithm settings for the 60 radiographs analyzed, the adaptive tracking was never lost. radiographs highlight natural texture. c) Deformation $u_{\mathrm{Y}}, u_{\mathrm{X}}$ and strain fields $\varepsilon_{\mathrm{YY}}, \varepsilon_{\mathrm{XX}}$ estimated across the thickness Y. d) The deformation correction (ANRC) reveals a negative moisture content $\omega$ gradient between moist and dry sample surfaces, in agreement with Fick's Law

The average strains calculated for each sample and sorption state for neutron (ANRC) and optic (DIC) images agreed closely, with $0.13 \% \mathrm{rms}$ error for $\varepsilon_{R R}$ and $0.44 \%$ for $\varepsilon_{T T}$ (Fig. 6b). Random uncertainties between the deformation fields estimated with both methods (Fig. 4b) were reduced for the average growth ring profiles. The flat $\varepsilon_{T T}$ profiles calculated with DIC were closely reproduced with ANRC (Fig. 5b). However, the intra-ring $\varepsilon_{R R}$ profiles showed significantly smoother trends for ANRC than for DIC (Fig. 5c). This a consequence of the large subset size $\Delta$ required for ANRC $\left(2.9 \times 2.9 \mathrm{~mm}^{2}\right)$ in comparison to DIC $\left(0.7 \times 0.7 \mathrm{~mm}^{2}\right)$, which matched the mean growth wing width $(2.8 \mathrm{~mm})$. For ANRC, the resolution of $\varepsilon_{R R}$ was limited by the thin LW layers, which were the dominating texture feature in the radiograph correlation. This led to stepped vertical patterns in $u_{X}$, which were not present in the DIC fields (Fig. 4c). Due the resolution loss, the peak value of $\varepsilon_{R R}$ in the ANRC profiles was displaced towards the center of the growth ring (Fig. 5b). The same effect is observed by comparing the DIC strains of Fig. $5 \mathrm{~b}$ with the higher resolution profiles (subset $0.2 \times 0.2 \mathrm{~mm}^{2}$ ) of Fig. $2 \mathrm{~d}$.

The average $\omega$ values calculated with ANRC agreed well with gravimetric measurements (Fig. 6a). Since the calculation of the neutron $\omega$ values is based on Equation 1, Fig. 6a experimentally confirms the validity of the neutron massattenuation coefficient in water $(\Sigma / \rho)_{h}=0.35 \mathrm{~m}^{-2} \mathrm{~kg}^{-1}$ [43] to quantitatively measure bound moisture in wood. The $0.9 \%$ rms uncertainties in $\omega$ were equivalent to the reported values with combined neutron/optic DIC measurements, and are 
Fig. 8 Simultaneous imaging of hygroscopic moisture transport and swelling in wood-fiber composites. a) Experimental timespace moisture content $\omega$ distribution (top) and simulation fit (bottom) for test sample of Fig. 7. b) Regression of unsteady state diffusion coefficients (neutrons) with steady state values (dry/wet cup). c) and d) show the time evolution of $\omega$ with respect to thickness swelling $\varepsilon_{\mathrm{YY}}$ in the moist Isoroof layers for six test samples $\left(\mathrm{L} 1_{1}\right.$ to $\left.\mathrm{L} 1_{6}\right)$, e) plots together the $\left(\omega, \varepsilon_{\mathrm{YY}}\right)$ pairs, revealing two differentiated hygroscopic swelling regimes

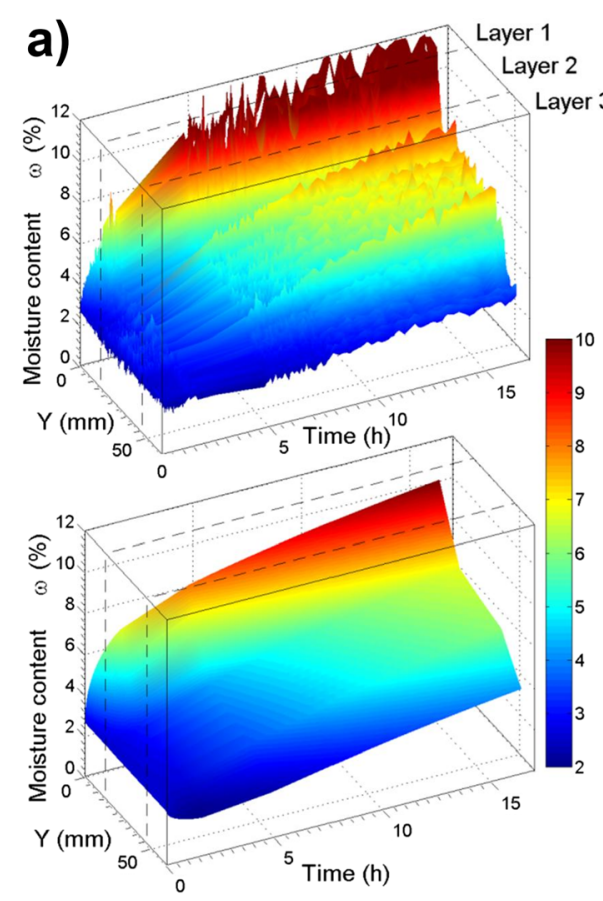

c)

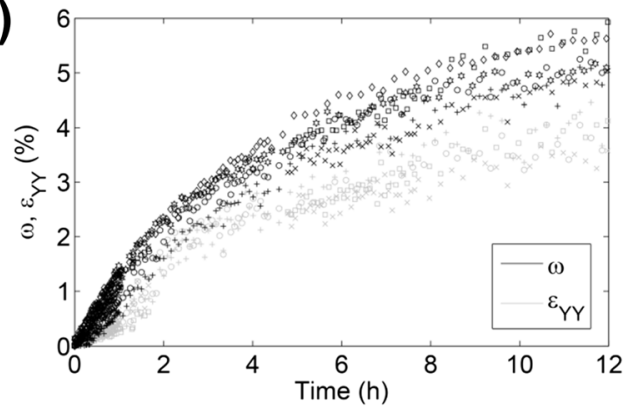

d)
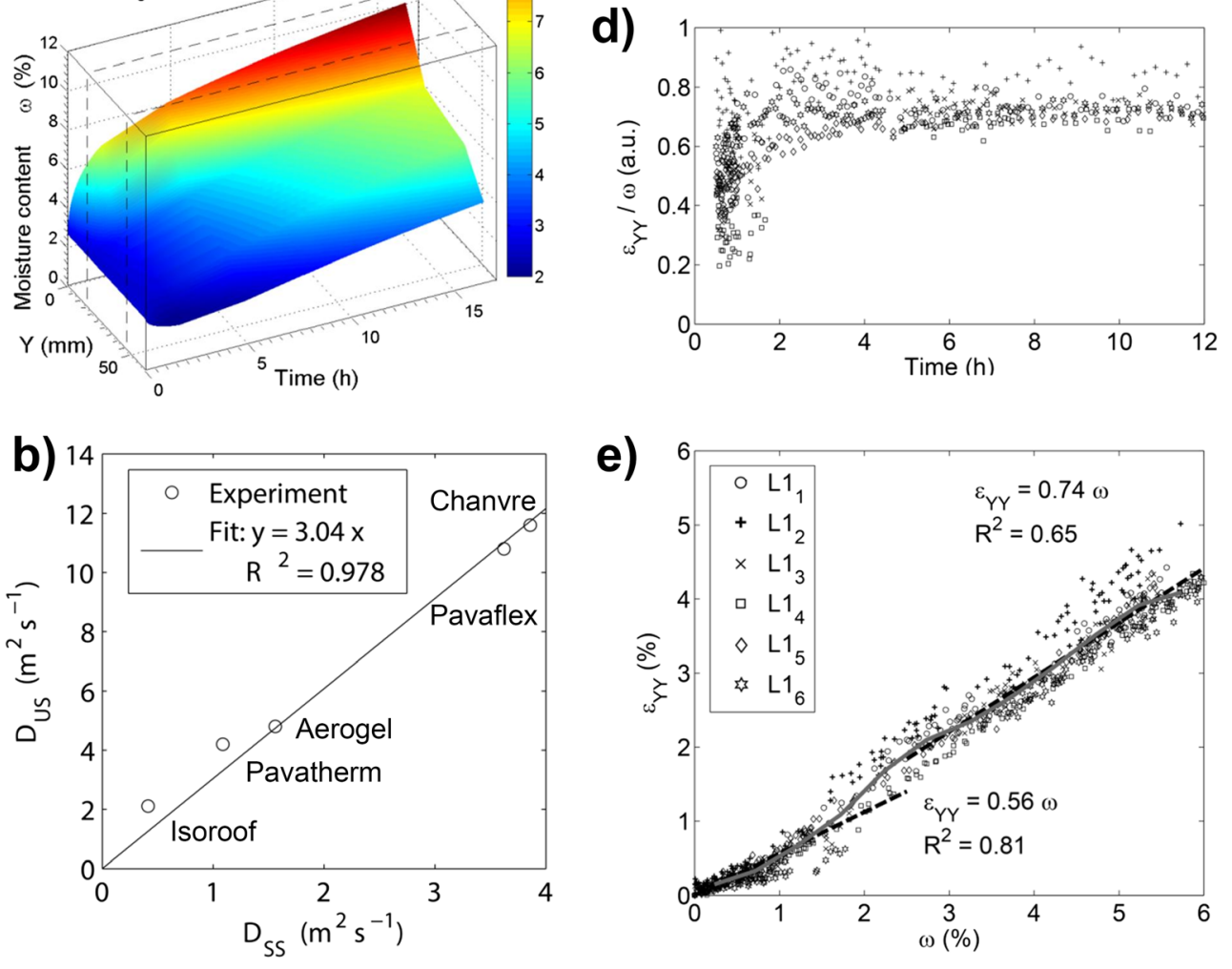

e)

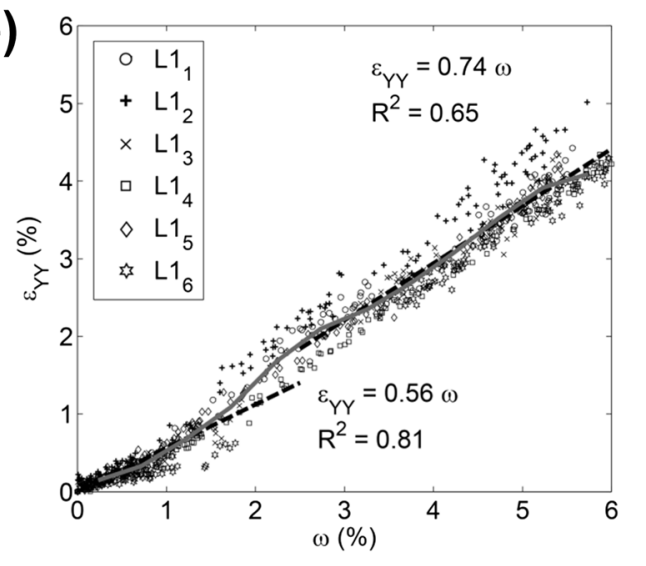

mainly due to residual background neutron scattering induced by the climatic box [15]. Neglecting the swelling strains (No corr.) led to unacceptable $\omega$ errors of $5 \%$ for $\varepsilon_{R R}+\varepsilon_{T T}$ up to $8 \%$, in close agreement with Equation 3. The moisture content $\omega$ follows a flat trend within the growth ring, since it scales with the bound water concentration in the cell walls, which in equilibrium conditions is evenly distributed [15, 22]. Combined neutron imaging and optic surface deformation (NI/DIC) confirmed within $\varphi=0 \ldots 0.7$ a constant $\omega$ with a rms error of $0.26 \%$ (Fig. 5d, [15]). However, due to the sharp density transition at LW-EW interfaces (Fig. 5a), the region $\varphi=0 \ldots 0.3$ showed strong edge misalignment artifacts and could not be resolved (Fig. 5d). Based only on the neutron radiographs, ANRC successfully removed these artifacts (Fig. 5e), capturing better the volumetric edge information than DIC optic surface measurements. Fig 5e shows a slight peaking around $\varphi=0.5$, due to the lower resolution of the estimated $\varepsilon_{R R}$ profiles (Fig. 5c) with respect to the neutron radiographs $T, T_{o}(\sim 0.7 \mathrm{~mm}, 3.1 .2)$. This peaking can be removed by pre-smoothing $T, T_{o}$ to the ANRC subset size $\left(2.9 \times 2.9 \mathrm{~mm}^{2}\right)$ before applying Equation 1 (data not shown). If the NI/DIC experimental setup is available, a better intraring resolution is achieved by aligning the neutron radiographs with ANRC and by inserting in Equation 1 the higher resolution strain fields $\left(0.7 \times 0.7 \mathrm{~mm}^{2}\right)$ calculated with DIC (Fig. 5f). A constant $\omega$ with an rms error of $0.18 \%$ is then assessed for the full growth ring $\varphi=0 \ldots 1$.

The discussion is completed by comparing NI and ANRC with other imaging technologies applied in wood science. NMR with isotope selectivity allows moisture measurements without dry state referencing, yet the point-wise testing scheme becomes time-prohibitive for full-field imaging [22]. TC algorithms have been applied to X-ray synchrotron tomograms with micrometer resolution to study hygroscopic cell 
wall swelling [32]. At this scale, the high contrast between cell wall and lumen voids allows correlation without need of adaptive search. Non-adaptive TC was indirectly applied to $\mathrm{X}$-ray radiographs of sub-millimeter resolution to monitor wood shrinkage during drying [33]. Dry state images were aligned to specific moisture states with a global pre-registering method, then TC was used to quantify strain out of the transformed dry-state images. In comparison, the proposed ANRC algorithm is able to locally resolve inhomogeneous strain fields, while performing satisfactorily at a resolution scale for which subcellular features are homogenized.

\section{Transient moisture diffusion and moisture-induced swelling in wood-fiber composites}

Figure 7a shows neutron radiographs of an Isoroof-PavaflexIsoroof composite at the beginning and end of the $17 \mathrm{~h}$ diffusion experiment. A profile in thickness direction (Y) clearly reveals the moisture-induced deformation, and shows a strong contrast between the dense outer layers and the lighter middle layer (Table 1). The image preprocessing step (Fig. 7b) improves the lateral resolution of the strain fields by filtering out sample edges and interfaces between composite layers, which would otherwise dominate the correlation process. This highlights the local natural texture, which shows reproducible random patterns in dry $I^{r e f}$ and moist $I^{\text {test }}$ states that lead to unique correlation peaks in $I^{\text {corr }}$. The peaks are here less sharp than in optical measurements with artificial speckling (Fig. 2b), due to the coarser texture in neutron images, which also requires larger subset sizes $\left(4.5 \times 9 \mathrm{~mm}^{2}\right)$. The deformation fields showed complex patterns (Fig. 7c), which were found reproducible for smaller $\left(3 \times 6 \mathrm{~mm}^{2}\right)$ and larger $(6 \times$ $12 \mathrm{~mm}^{2}$ ) subset sizes. The up to $11 \%$ thickness swelling strains $\varepsilon_{Y Y}$ were about 20 times larger than in-plane strains $\varepsilon_{X X}$, due to the inner stresses introduced by hot panel pressing, which induce a springback effect [17]. The dense outer layers exerted a strong compressive force upon the lighter middle layer, for which negative strain values were measured. The compressive strains were largest close to the moist layer interface.

Uncorrected for deformation (Fig. 7d), the calculated $\omega$ profiles across the composite thickness apparently contradicted Fick's second law, which predicts negative gradients in bound water concentration between moist and dry interfaces [34]. The large thickness swelling strains strongly influenced the calculation, accounting for up to $50 \%$ of $\omega$. After correction, monotonically decreasing $\omega$ profiles were obtained, which allowed the optimization of $D_{U S}$ with Equation 6. The simulated and experimental time-space moisture distributions were in good agreement, with rms $\omega$ errors of $0.6 \%$ (Fig. $8 \mathrm{a}$ ). The small oscillations at layer interfaces are associated to moisture barrier effects and to volumetric edge artifacts. The optimized unsteady state diffusion coefficients
$D_{U S}$ showed a strong correlation $\left(R^{2}=0.978\right)$ with the steady state coefficients $D_{S S}$ obtained with the dry/wet cup method (Fig. 8b). The approximately three times scale factor between $D_{U S}$ and $D_{S S}$ is consistent with previous observations in solid wood [3], and is associated to the different diffusion regimes and simplifications in the modelling. For instance, the sorption coupling between water vapor and bound water transport, which is a function of the detailed material microstructure and is in general not known, needs to be included in Equation 6 to avoid sample thickness-dependent $D_{U S}$ [23].

Figure $8 \mathrm{c}$ shows the time evolution of the strain fields $\varepsilon_{Y Y}$ and moisture content $\omega$, averaged over the first Isoroof layer for each of the six tested samples. Both $\varepsilon_{Y Y}$ and $\omega$ showed monotonically increasing trends, which flattened at equilibrium moisture content ( $\mathrm{t}>12 \mathrm{~h})$. The ratio $\varepsilon_{Y Y} / \omega$ (Fig. $\left.8 \mathrm{~d}\right)$ increased for $\mathrm{t}<4 \mathrm{~h}$ and then approached a constant differential swelling $q_{Y}$. A time delay of the swelling with respect to the originating moisture content was hypothesized and tested by fitting exponential laws $\varepsilon_{Y Y} / \omega=q_{Y}\left[1-\exp \left(-\mathrm{t} / \tau_{\varepsilon}\right)\right] /[1-\exp (-\mathrm{t} /$ $\left.\left.\tau_{\omega}\right)\right]$ to the time-dependent trends of both $\varepsilon_{Y Y}$ and $\omega$. The average $\tau_{\omega}=5.1 \mathrm{~h}$ and $\tau_{\varepsilon}=5.8 \mathrm{~h}$ suggest a viscoelastic hygromechanical behavior, with a delay of $0.7 \mathrm{~h}$ between moisture and moisture-induced deformation. However, the hypothesis $\tau_{\varepsilon}<\tau_{\omega}$ could only be rejected with a t-test above a $20 \%$ confidence level, which throws doubts on such a delay mechanism. Moreover, the flattening of $\varepsilon_{Y Y} / \omega$ occurs rather abruptly. Next, a possible moisture-dependent $q_{Y}$ was tested by plotting all available $\left(\varepsilon_{Y Y} \omega\right)$ pairs in a single plot (Fig. $8 \mathrm{e}$ ), and by extracting a continuous trend with clustering [35]. A master trend between moisture and strain fields was revealed, with differentiated swelling regimes for $\omega<2 \%\left(\varepsilon_{Y Y}=0.56 \omega\right)$ and $\omega>3 \%\left(\varepsilon_{Y Y}=0.74 \omega\right)$. This behavior can be interpreted by considering that in dry state, the lignocellulosic cell wall shows a low porosity where water molecules find readily available sorption sites (chemisorption). As further sorption takes place (physisorption), the water molecules contribute their full volumes to the cell wall, which is accompanied by higher swelling $[7,36]$. The transition region $\omega=2 \ldots 3 \%$ was consistent with observations at hygroscopic equilibrium [37, $38]$.

\section{Conclusions and Outlook}

Neutron imaging together with ANRC processing is able to simultaneously image moisture and moisture-induced deformation fields with high spatial and temporal resolution, with opens new horizons for the hygromechanical characterization of highly swelling materials, as found in wood constructions, but as well in food and agricultural industry, engineering and soil science [6]. One additional advantage of ANRC is that it can be easily implemented as software postprocessing of 
neutron images, therefore requiring no modification of available neutron installations.

Applied to the investigation of hygroscopic gradients in softwood growth rings, ANRC provided an excellent agreement with gravimetric moisture content $(0.9 \% \mathrm{rms}$ error $)$ and optic surface strain measurements $(0.5 \%$ error $)$, with similar uncertainties to the ones reported with combined neutron and optic methods. Moreover, ANRC achieved better edge alignment than optic surface deformation measurements [15], allowing to assess a flat moisture trend $(0.18 \% \mathrm{rms}$ error $)$ even at latewood-earlywood discontinuities. The strain fields estimated with ANRC showed lower resolution than optical measurements, due to the large subset sizes required to capture natural texture. In resolution-critical scenarios, ANRC can be used for radiograph alignment and optic methods can be applied for strain estimation. The ANRC algorithm is readily extensible to three-dimensional stacks as provided by neutron computed tomography. In the hygroscopic range analyzed, the moisture fields were smoother than the texture of the solid phase and represented $<10 \%$ of the neutron transmission scale, therefore they did not need to be explicitly accounted for in the correlation procedure. Above saturation, liquid water may lead to stronger contrast differences [19], which can be removed by iteratively subtracting the moisture fields from the radiographs.

Applied to the study of moisture transport in highly hygromorphic wood-fiber composites, the ANRC correction enabled the otherwise not possible optimization of moisture diffusion coefficients, which showed a strong correlation $\left(R^{2}=0.978\right)$ with steady state values. Moreover, ANRC provided in-deep understanding of the time development of swelling strains with respect to the originating moisture fields. The results do not clearly support a delay mechanism between strain and moisture fields. However, higher differential swelling coefficients could be assessed in physisorption than in chemisorption regimes. Experimental studies of the rheology of moisture-induced deformation fields have been so far rare, due to the practical challenges in simultaneously mapping time-dependent moisture and strain fields. The ANRC method can contribute to the understanding of mechano-sorptive effects [39]. Another application field is envisaged in the development and characterization of hygromorph composites, which respond to environmental humidity by reproducibly changing their shape [40].

\section{References}

1. Kardjilov N, Manke I, Hilger A, Strobl M, Banhart J (2011) Neutron imaging in materials science. Mater Today 14(6):248-256

2. Lehmann E, Vontobel P, Kardjilov N (2004) Hydrogen distribution measurements by neutrons. App Radiat Isot 61:503-509
3. Mannes D, Sonderegger W, Hering S, Lehmann E, Niemz P (2009) Non-destructive determination and quantification of diffusion processes in wood by means of neutron imaging. Holzforschung 63: 589-596

4. Perfect E, Cheng CL, Kang M, Bilheux HZ, Lamanna JM, Gragg MJ, et al. Neutron imaging of hydrogen-rich fluids in geomaterials and engineered porous media: a review. Earth Sci Rev. 2013.

5. Strobl M, Manke I, Kardjilov N, Hilger A, Dawson M, Banhart J (2009) Advanced in neutron radiography and tomography. J Phys D Appl Phys 42:243001

6. Katekawa ME, Silva MA (2006) A review of drying models including shrinkage effects. Drying Technol 24(1):5-20

7. Skaar C (1988) Wood-water relations. Springer, Berlin

8. Bledzki AK, Gassan J (1999) Composites reinforced with cellulose based fibers. Prog Polym Sci 24:221-274

9. Sonderegger W, Niemz P (2006) Investigation of swelling and thermal expansion of fibreboard, particleboard and plywood. Eur J Wood Wood Prod 64:11-20

10. Muszynski L (2006) Empirical data for modeling: methodological aspects in experimentation involving hygromechanical characteristics of wood. Drying Technol 24(9):1115-1120

11. Hussey DS, Sepernjak D, Weber AZ, Mukundan R, Fairweather J, Brosha EL et al (2012) Accurate measurement of the through-plane water content of proton-exchange membranes using neutron radiography. J Appl Phys 112:104906

12. Derome D, Rafsanjani A, Hering S, Dressler M, Patera A, Lanverman C et al (2013) The role of water in the behavior of wood. J Build Phys 36(4):398-421

13. Datta AK (2007) Porous media approaches to studying simultaneous heat and mass transfer in food processes II: Property data and representative results. J Food Eng 80:96-110

14. Mihoubi D, Bellagi A (2012) Modeling of heat and moisture transfers with stress-strain formation during convective air drying of deformable media. Heat Mass Transfer 48:1697-1705

15. Lanverman C, Sanabria SJ, Mannes D, Niemz P (2014) Combination of neutron imaging (NI) and digital image correlation (DIC) to determine intra-ring moisture variation in Norway spruce. Holzforschung 68(1):113-122

16. Rosner S, Riegler M, Vontobel P, Mannes D, Lehmann E, Karlsson B et al (2012) Within-ring movement of free water in dehydrating Norway spruce sapwood visualized by neutron radiography. Holzforschung 66:751-756

17. Sonderegger W, Hering S, Mannes D, P V, Lehmann E, Niemz P. Quantitative determination of bound water diffusion in multilayer boards by means of neutron imaging. Eur J Wood Wood Prod. 2010;68:341-350

18. Mannes D, Sanabria SJ, Funk M, Wimmer R, Kranitz K, Niemz P. Water vapour diffusion through historically relevant glutin-based wood adhesives with sorption measurements and neutron radiography. Wood Sci Technol. 2014;(In print).

19. Sedighi-Gilani M, Vontobel P, Lehmann E, Carmeliet J, Derome D. Liquid uptake in Scots pine sapwood and hardwood visualized and quantified by neutron radiography. Mater Struct. 2013

20. Aregawi W, Defraeye T, Saneinejad S, Vontobel P, Lehmann E, Carmeliet J et al (2013) Dehydration of apple tissue: Intercomparison of neutron tomography with numerical modelling. Int J Heat Mass Transfer 67:173-182

21. Fu RS, Pasaogullari U, Shiomi T, Tabuchi Y, Hussey DS, Jacobson DL (2012) High-resolution neutron radiography of through-plane liquid water distribution in polymer electrolyte membrane and gas diffusion layer. J Electrochem Soc 159(9): F545-F553

22. Dvinskikh SV, Henriksson M, Berglund LA, Furó I. A multinuclear magnetic resonance imaging (MRI) study of wood with adsorbed water: estimating bound water concentration and local wood density. Holzforschung. 2011;65(103-107). 
23. Eitelberger J, Hofstetter K, Dvinskikh SV. A multi-scale approach for simulation of transient moisture transport processes in wood below the fiber saturation point. Compos Sci Technol. 2011;71(1727.1738).

24. Lanverman C, Falk W, Niemz P (2014) Full-field moisture induced deformation in Norway spruce: intra-ring variation of transverse swelling. Eur J Wood Wood Prod 72:43-52

25. Rafsanjani A, Lanverman C, Niemz P, Carmeliet J, Derome D (2013) Multiscale analysis of free swelling of Norway spruce. Compos Part A-Appl S 54:70-78

26. Brombacher V, Michel F, Volkmer T, Niemz P (2012) Investigation of thermal conductivity and moisture behaviour of fibreboard and material combinations. Bauphysik 34(4):157-169

27. Sutton MA, Orteu J, Schreier HW (2009) Image Correlation for Shape, Motion and Deformation Measurements. Springer, New York, NY, USA

28. Bay BK (2008) Methods and applications of digital volume correlation. J Strain Anal Eng 43:745

29. De Boor C (2001) A practical guide to splines. Springer, New York, NY, USA

30. Michel F. Bestimmung bauphysikalisch relevanter Eigenschaften bei Materialkombination von porösen Holzfaserplatten und anderen Materialien Bachelor Thesis. Bern University of Applied Sciences AWCE, 2012

31. Gibson LJ, Ashby MF (1997) Cellular solids: structure and properties. Cambridge University Press, Cambridge

32. Forsberg F. X-ray microtromography and digital volume correlation for internal deformation and strain analysis $\mathrm{PhD}$ Thesis. Lulea University of Technology, 2008.

33. Watanabe K, Lazarescu C, Shida S, Avramidis S (2012) A novel method of measuring moisture content distribution in timber during drying using CT scanning and image processing techniques. Drying Technol 30:256-262
34. Crank J (1975) The mathematics of diffusion. Oxford University Press, New York, NY, USA

35. Sanabria SJ, Hilbers U, Neuenschwander J, Niemz P, Sennhauser U, Thömen $\mathrm{H}$ et al (2013) Modeling and prediction of density distribution and microstructure in particleboards from acoustic properties by correlation of non-contact high-resolution pulsed air-coupled ultrasound and X-ray images. Ultrasonics 53:157-170

36. Derome D, Rafsanjani A, Patera A, Guyer R, Carmeliet J (2012) Hygromorphic behaviour of cellular material: hysteretic swelling and shrinkage of wood phrobed by phase contrast X-ray tomography. Phylos Mag A 92:3680-3698

37. Keylwerth R (1964) Investigations on the course of swelling and the dependence of wood density on moisture. Eur J Wood Wood Prod 22: 255-258

38. Popper R, Niemz P, Eberle G (2008) Discussion of the interaction between wood and water based on selected foreign wood species as examples, and the concept of hypothetical hydration water. Bauphysik 30(5):333-339

39. Svensson S, Toratti T (2002) Mechanical response of wood perpendicular to grain when subjected to changes of humidity. Wood Sci Technol 36:145-156

40. Burgert I, Fratzl P (2009) Actuation systems in plants as prototypes for bioinspired devices. Phylos Mag A 367:1541-1557

41. Lehmann EH, Vontobel P, Wiezel L (2001) Properties of the radiography facility NEUTRA at SINQ and its potential for use as a European Reference Facility. Nondestr Testing Eval 16:191-202

42. Mannes D, Josic L, Lehmann E, Niemz P (2009) Neutron attenuation coefficients for non-invasive quantification of wood properties. Holzforschung 63(4):472-478

43. Hassanein R K. Correction methods for the quantitative evaluation of thermal neutron tomography. PhD Thesis. ETH Zurich, 2006. 